\title{
Sentido e possibilidades da aula de Filosofia no Ensino Médio
}

Karen Giovana Videla da Cunha Naidon

Mestranda em Filosofia na Universidade Federal de Santa Maria-RS

\section{Resumo}

O presente artigo tem por objetivo abordar as seguintes questões: "Qual o sentido da aula de filosofia no ensino médio?" e "Quais as possibilidades da aula de filosofia no ensino médio?”. Ao longo do trabalho, chega-se à conclusão de que uma aula de filosofia deve ensinar os alunos a filosofar, tendo-se em conta os procedimentos desenvolvidos por diferentes filósofos ao longo da história, com o que estaria dando ao aluno contribuições valiosas. Contudo, pode ser detectada a existência de alguns entraves para a disciplina de filosofia no ensino médio, para cuja neutralização propõe-se, neste artigo, o recurso à metodologia desenvolvida por Gallo (2007, p. 15-36).

Palavras-chave: Ensino; Filosofia; Ensino médio.

\begin{abstract}
This article aims to address the questions: "What is the sense of philosophy class in high school?" and "What the possibilities of philosophy class in high school?". Throughout the paper, one comes to the conclusion that a philosophy class must to teach students to how to philosophize, taking into account the procedures developed by different philosophers throughout history, with what is giving to the student valuable contributions. However, it can be detected the existence of some barriers to the discipline of philosophy in high school, which can be overcome, it is proposed in this article, using the methodology developed by Gallo (2007, p. 15-36).
\end{abstract}

Keywords: Teaching; Philosophy; High school.

(C) Filosofia e Educação - ISSN 1984-9605 - Volume 4, Número 2

Outubro de 2012 - Março de 2013 


\section{Introdução}

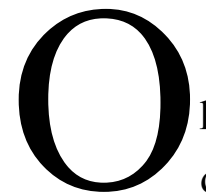
presente artigo pretende abordar duas questões que devem ser postas e, ao menos provisoriamente, respondidas pelo professor de filosofia antes que o mesmo adentre em sala de aula: "Qual o sentido da aula de filosofia no ensino médio?" e "Quais as possibilidades da aula de filosofia no ensino médio?”. A primeira questão, acerca do sentido da aula de filosofia, visa à obtenção de uma resposta acerca da função da disciplina de filosofia para o ensino médio, ou seja, o que o professor de filosofia deve ter em mente como o objetivo a ser alcançado através de suas aulas, qual a contribuição que ele pode oferecer para a formação de seus alunos. A segunda questão, sobre as possibilidades práticas quando da realização dessas aulas, pretende indicar os limites e dificuldades que serão enfrentados pelo professor de filosofia para a consecução de seu objetivo e, desse modo, fornece subsídio para que seja por ele traçada, ao menos em linhas gerais, uma possível estratégia de ação a ser posta em prática em sala de aula.

O professor de filosofia deve propor-se a responder ambas as questões porque a aula de filosofia que por ele será ministrada dependerá, em grande medida, de seu posicionamento frente a tais questionamentos. Diante disso, é de suma importância abordar o tema, mesmo que superficialmente, como será feito neste trabalho.

A despeito de abordar ambas as questões recém elencadas, o presente trabalho pretende conferir maior ênfase à questão concernente às possibilidades da aula de filosofia, tentando esboçar uma visão própria, embora embasada na literatura sobre o tema, acerca de como planejar uma aula de filosofia para o ensino médio, tendo em vista as condições atuais do ambiente escolar. Para tanto, divide-se o trabalho em duas partes principais.

(C) Filosofia e Educação - ISSN 1984-9605 - Volume 4, Número 2 Outubro de 2012 - Março de 2013 
Na primeira delas, aborda-se a questão de qual sentido se atribui ao ensino de filosofia no ensino médio. Na segunda parte, é tratada a questão das possibilidades da aula de filosofia no ensino médio, discorrendo-se brevemente sobre as condições atuais da filosofia no ensino médio e sobre qual estratégia que o professor poderia adotar na execução de sua tarefa de fazer com que a filosofia cumpra seu papel.

\section{Qual o sentido da aula de filosofia no ensino médio?}

Antes de indagar-se sobre o sentido da aula de filosofia, isto é, de ensinar filosofia aos alunos do ensino médio, cumpre a todo aquele que é ou pretende ser professor de filosofia responder a seguinte questão: o que será ensinado nessas aulas? Faz-se necessário responder a essa questão porque o sentido da aula de filosofia, a contribuição que ela dará para as vidas dos alunos depende do que será ensinado em sala de aula.

Ao perguntar-se sobre o que será ensinado nas aulas de filosofia, poder-se-á obter a seguinte resposta de imediato: ora, filosofia. Contudo, vale notar não haver um consenso acerca do que seja filosofia. Alguns dirão que filosofia é o produto, o resultado do processo de filosofar desenvolvido pelos filósofos e, com isso, o que deveria ser ensinado aos alunos é esse produto, ou seja, a história da filosofia. Outros dirão que filosofia não é o produto, mas sim o próprio processo e, nesse sentido, o que deveria ser ensinado é a filosofar.

Poder-se-á ainda dizer que, como tantos outros questionamentos filosóficos, a pergunta acerca do que seja filosofia jamais terá uma resposta conclusiva, ou melhor, uma resposta que gere consenso, pois cada um fornecerá a sua própria resposta e não a concederá a seu oponente. Ainda que isso ocorra, a pergunta deve ser respondida, ao menos provisoriamente, por todo professor ou futuro professor de filosofia. Isso porque de sua resposta depende a resposta à questão sobre qual o sentido da filosofia e esta

(C) Filosofia e Educação - ISSN 1984-9605 - Volume 4, Número 2 Outubro de 2012 - Março de 2013 
será determinante para as aulas que esse professor ministrará no ensino médio.

Entre os estudiosos sobre o tema no Brasil, há autores renomados que sustentam não haver propriamente uma dissociação entre a história da filosofia e o filosofar. Nesse sentido, Gallo e Kohan (2000, p. 184) afirmam que "a própria prática da filosofia leva consigo o seu produto e não é possível fazer filosofia sem filosofar, nem filosofar sem fazer filosofia." Aspis (2004, p. 308), do mesmo modo, sustenta que:

[...] não é possível desunir filosofia de filosofar pois os dois são uma mesma coisa. O filosofar é uma disciplina no pensamento que ao ser operada vai produzindo filosofia e a filosofia é a própria matéria que gera o filosofar. São indissociáveis. A matéria filosofia separada do ato de filosofar é matéria morta, recheio de livro de estante. Para ser filosofia ela tem que ser reativada, reoperada, assim reaparecendo a cada vez. Como a malha tricotada que só aparece se houver o ato do tricotar.

Também nesse sentido é o posicionamento de Obiols, o qual recorre a Kant a fim de sustentar a indissociabilidade entre a história da filosofia e o filosofar. Para Kant (apud Obiols, 2002, p. 77),

Só é possível aprender a filosofar, ou seja, exercitar o talento da razão, fazendo-a seguir seus princípios universais em certas tentativas filosóficas já existentes, mas sempre reservando à razão o direito de investigar aqueles princípios até mesmo em suas fontes, confirmando-os ou rejeitando-os.

A partir dessa passagem, vê-se que o filosofar é feito a partir do legado deixado pela tradição filosófica. Nesse sentido, o filosofar não ignora a história da filosofia e, por isso, não se dissocia dela. Contudo, a história da filosofia não seria o suficiente. O filosofar, com base no que está posto até então, o pôr o pensamento em movimento seria o essencial.

Com base nesses autores, pode-se afirmar que uma resposta do que seja filosofia esteja no filosofar. Contudo, esse filosofar não dispensa o

(C) Filosofia e Educação - ISSN 1984-9605 - Volume 4, Número 2

Outubro de 2012 - Março de 2013 
recurso à história da filosofia, uma vez que o pensamento filosófico é posto em movimento a partir do contato com as "tentativas filosóficas já existentes" - para usar a mesma expressão de Kant. Com efeito, é assim que os filósofos filosofam. Por que não tentar fazer o mesmo nas aulas de filosofia do ensino médio?

Diante dessa resposta, o que deve ser ensinado nas aulas de filosofia é o filosofar, mas recorrendo-se ao que os filósofos desenvolveram. Ao ensinar a filosofar, está-se ensinando o aluno a pensar por si próprio. Esse pensar por si próprio é um pensar que busca razões para sustentar suas conclusões; sendo assim, não assume determinado posicionamento por força de qualquer autoridade. Ao ensinar isso ao aluno, ensina-se o mesmo a ser filósofo. Caso o ensino de filosofia seja limitado à história da filosofia, estar-se-á impondo certas idéias aos alunos, as quais, em última instância (na medida que os argumentos dos filósofos não fossem capazes de sustentar suas posições), serão sustentadas em virtude da mera autoridade dos próprios filósofos. Tal proceder, contudo, é contrário à própria filosofia, é contrário ao modo como procederam os filósofos ao longo da história. Por isso, diante da natureza da filosofia, é necessário um esforço por parte do professor do ensino médio no sentido de estimular seus alunos a elaborarem convicções próprias a respeito do que está sendo tratado em aula, seja para concordar, seja para discordar do que os filósofos disseram.

Aspis $(2004$, p. 310 ) elabora com alguns acréscimos o que se tenta expressar acima, ao falar das aulas de filosofia como um lugar para a experiência filosófica. Conforme a autora:

As aulas de filosofia, como lugar da experiência filosófica, têm como objetivo oferecer critérios filosóficos para o aluno julgar a realidade por meio da prática do questionamento filosófico e da construção de conceitos, por meio do exercício da criatividade e avaliação filosóficas. Assim, além dos critérios e do modo de pensar da indústria, do consumismo ou da mídia, além dos critérios e do modo de pensar da tradição e da ciência, o aluno

(C) Filosofia e Educação - ISSN 1984-9605 - Volume 4, Número 2

Outubro de 2012 - Março de 2013 
passará a dispor dos critérios e do modo de pensar da filosofia para compor seu pensamento de forma autônoma, pois autoconsciente e, portanto, metacognitivo.

Por fim, após chegarmos aqui a uma conclusão, ao menos provisória, do que seja filosofia e, portanto, do que deve ser ensinado nas aulas de filosofia, está-se em condições de responder, também provisoriamente, a questão acerca do sentido da filosofia no ensino médio, isto é, da contribuição que a filosofia pode dar para a formação do aluno do ensino médio.

Dadas as características que a aula de filosofia deve ter, sua presença no ensino médio pode ser capaz, caso atinja êxito, de contribuir para o desenvolvimento da capacidade crítica do aluno. Aprender a fazer o processo argumentativo desenvolvido no filosofar, o qual se guia pela busca de razões, pode contribuir para que o aluno se torne alguém que pensa autonomamente (se é que ele ainda não é), alguém que não aceita imposições, alguém que raciocina. Tal contribuição não é nem um pouco pequena. Em verdade, não é tão fácil encontrar pessoas assim. Com efeito, de acordo com Gallo (2007, p. 22), “[...] a atitude filosófica é a da nãoconformação, do questionamento constante, da busca das raízes das coisas, não se contentando com respostas prontas e sempre colocando em xeque as posturas dogmáticas e as certezas apressadas." Desse modo, uma das principais características da filosofia, para o autor, seria possibilitar "uma postura crítica radical", o que vai ao encontro do que foi dito recém a respeito da filosofia contribuir para que o aluno tenha um pensamento autônomo.

Gallo aponta, ainda, uma segunda característica da filosofia, a saber, apresentar "um caráter dialógico". Conforme Gallo (2007, p. 22), a filosofia "não se caracteriza como um saber fechado em si mesmo, uma verdade dogmática, mas como um saber que se experimenta, que se confronta 
consigo mesmo e com os outros, que se abre ao diálogo com outros saberes, um saber aberto e em construção coletiva." Tendo essa característica, a filosofia poderia contribuir para que o aluno tenha uma visão mais ampla e articulada dos conhecimentos que adquire na escola, ou mesmo fora dela, uma vez que, em dialogando com outros saberes, ela permite que sejam tornadas mais claras as inter-relações existentes entre diferentes áreas do saber, dentre elas, a própria filosofia.

Além dessas duas características, Gallo aponta uma terceira: a filosofia, para ele, é a atividade de criação de conceitos. Aqui, o autor baseia-se na filosofia de Deleuze e Guatarri. Estes autores distinguem entre três potências do pensamento: o pensamento científico, o artístico e o conceitual. As três formas de pensamento propiciam, através do enfrentamento de uma situação caótica, a emergência da criatividade humana. O resultado obtido, contudo, divergirá: o pensamento científico resultará em funções; o pensamento artístico, em perceptos e afectos; e o pensamento conceitual, em conceitos. (Gallo, 2007, p. 20)

Essa noção de conceito, entretanto, destoa do modo como normalmente a noção é entendida no âmbito da filosofia, do senso comum ou mesmo das ciências. O que Deleuze e Guatarri entendem por "conceito" não é uma noção, definição ou representação mental, alguma entidade transcendente que se aplica às coisas. De acordo com Gallo (2007, p. 23), o conceito, para eles, é "uma forma racional de equacionar um problema ou problemas, exprimindo uma visão coerente do vivido; isto é, o conceito é uma forma de lançar inteligibilidade sobre o mundo." O filósofo, então, deparando-se com um problema concreto por ele vivido, tenta equacioná-lo racionalmente. Esse movimento, essa atividade de equacionar o problema é, na visão de Deleuze e Guatarri, um conceito. (Gallo, 2007, pp. 23-24)

Segundo Gallo, esta terceira característica da filosofia, ou seja, o fato de ela consistir na atividade de criação de conceitos, é que determinaria a

(C) Filosofia e Educação - ISSN 1984-9605 - Volume 4, Número 2 Outubro de 2012 - Março de 2013 
sua especificidade, uma vez que se trata da única característica que lhe é exclusiva, que não é partilhada por nenhuma outra área do saber. Diante disso, a presença da filosofia nos currículos de ensino médio torna-se indispensável, já que nenhuma outra disciplina é capaz de proporcionar tamanha oportunidade aos alunos: a oportunidade de exercerem o pensamento conceitual. Como o ensino médio constitui a última etapa da educação básica, é salutar que essa oportunidade seja dada ao aluno durante o mesmo. Isso porque, como coloca Gallo (2007, p. 21),

Aqueles que concluirão seus estudos nesse nível dificilmente terão outras oportunidades de encontro com tais experiências; por outro lado, aqueles que farão estudos universitários provavelmente enveredarão por uma dessas áreas [científica, artística ou filosófica], especializando-se, sem maiores oportunidades de experimentar as outras potências de pensamento.

Este é, de forma resumida, o argumento de Gallo para justificar a presença da filosofia no ensino médio, isto é, propiciar a experiência de criação de conceitos, argumento ao qual se adere neste trabalho.

Não obstante, vale ressaltar que a contribuição da filosofia para os alunos do ensino médio é mais ampla do que aquela que determina sua especificidade. Ela proporciona, além de uma oportunidade para o exercício do pensamento conceitual, também a possibilidade desenvolvimento por parte do aluno da capacidade de pensar autonomamente, guiando-se por razões, bem como permite que o mesmo tenha maior facilidade para articular em sua mente os diferentes saberes com os quais tem contato, seja na escola ou fora dela. Eis o sentido da aula de filosofia no ensino médio, ou seja, a contribuição que a disciplina pode dar aos alunos. É a fim de efetuar essas possíveis contribuições que o professor deve pautar a organização de suas aulas de filosofia no ensino médio. A filosofia deve contribuir para o aluno do ensino médio com tudo aquilo que ela pode contribuir, desde que, com isso, não perca sua especificidade. Como ela pode realizar as três 
contribuições acima elencadas de forma concomitante, então ela deve fazêlo, e o professor deve se esforçar para tanto.

\section{Quais as possibilidades da aula de filosofia no ensino médio?}

Diante da conclusão a que se chegou na seção precedente acerca do que deve ser ensinado nas aulas de filosofia, ou seja, a filosofar, tomando como base os desenvolvimentos filosóficos que surgiram ao longo da história, cumpre então começar a discorrer sobre as possibilidades de efetuar tal ensino, tendo em vista a atual realidade em que se encontram inseridos tanto os alunos quanto a escola. Assim, passar-se-á a tecer considerações a respeito de tal realidade e, feito isso, tentar-se-á apontar uma possível estratégia a ser adotada.

\subsection{As condições atuais da filosofia na escola}

O título desta seção foi tomado do capítulo II do livro "A fílosofia no ensino médio", de Alejandro Cerletti e Walter O. Kohan, no qual é abordada a questão acerca de quais seriam as atuais condições da filosofia na escola dada a sociedade em que vivemos. Assim se procedeu pelo fato de que referido escrito servirá de base para o presente incurso.

Os autores introduzem o tema do capítulo a partir da exposição do atual contexto de nossa sociedade, que poderia ser chamada de "pósmoderna". Referida sociedade seria globalizada e, conforme os autores, seria regida pelas leis de mercado.

Dita globalização é resultado da atuação massiva dos meios de comunicação, através dos quais se pode obter informações a respeito de acontecimentos em praticamente todas as partes do mundo. Os indivíduos, assim, não têm seu mundo restrito ao local onde vivem, mas sim acabam ampliando suas fronteiras por meio de televisores, computadores, etc. É

(C) Filosofia e Educação - ISSN 1984-9605 - Volume 4, Número 2

Outubro de 2012 - Março de 2013 
nesse sentido que Cerletti e Kohan (1999, p. 38) afirmam que a "dinâmica dos meios de comunicação é também instrumento de globalização."

Contudo, ao mesmo tempo em que os meios de comunicação nos colocam em contato com a totalidade, que seria o restante do mundo, eles também contribuem para a ocorrência de uma reclusão individual, a qual se reflete na própria "imagem robótica e isolada que o 'walkman', o computador ou o vídeo mostram." (Cerletti e Kohan,1999, p. 38) Além dessa reclusão individual, desse recolhimento a uma atividade praticada individualmente por cada pessoa, há que ser ressaltada a dissolução da possibilidade de reflexão por parte do indivíduo, que é resultado da própria velocidade alta com que as informações lhes são transmitidas. Cerletti e Kohan (1999, p. 38) colocam nesse sentido: “[...] o mundo todo e toda a realidade são apresentados no vertiginoso ritmo do vídeo-clipe.”

Vale notar ainda que essa dinâmica dos meios de comunicação, por seu turno, é regida pelas leis de consumo. Isso ocorre porque tudo aquilo que pode ser obtido através dos meios de comunicação, tal como o que nos é transmitido por meio de televisores, computadores, etc., é obtido porque compramos esses aparelhos. Eles, com efeito, proporcionam ao homem pósmoderno aquilo que Cerletti e Kohan (1999, p. 38) chamaram de "prazer por quotas."

Nesse mesmo sentido, também, pode ser dito que até mesmo o sentido que se atribui ao termo "liberdade" passa a ser regido pelas leis de consumo. A liberdade, assim, é traduzida na liberdade de escolha que se tem na relação de consumo. Desse modo, na medida em que se tem poder aquisitivo, tem-se a liberdade de escolher entre várias opções de compra.

Cerletti e Kohan (1999, p. 39) recorrem a Foucault e às idéias de sociedade disciplinar e de sociedade de controle a fim de explicar o cenário da sociedade pós-moderna. As sociedades disciplinares, que tiveram seu apogeu no século $\mathrm{XX}$, eram organizadas em espaços-limite, nos quais os 
indivíduos eram disciplinados, isto é, o objetivo era "concentrar, dividir o espaço, ordenar no tempo". Os indivíduos aprendiam a disciplinar o próprio corpo e a atuar em conformidade com as normas relativas a cada espaçolimite. Um modelo visível de espaço-limite é fornecido pela fábrica, mas se pode falar ainda em outros espaços-limite, tais como a escola, a família, os hospitais, as penitenciárias, etc.

Tais sociedades, no entanto, entraram em crise, na medida em que todas estas instituições recém citadas têm sido questionadas. Atualmente, a sociedade disciplinar cedeu lugar para a sociedade de controle, na qual não há mais espaços-limite. A noção rígida de limite foi substituída pela de controle, que admite mudanças constantes, e tal controle não é mais exercido em espaços fechados (como os prédios da escola, do hospital, etc.). Com isso, tem-se a sensação de que se é livre, de que os atos não são determinados por forças alheias à vontade individual, o que constitui uma ilusão, já que todos somos constantemente controlados.

Todo esse controle, por sua vez, é determinado, é regido pelas leis de mercado. Em última instância, são essas leis, portanto, que regem cada indivíduo, que é moldado para ser um consumidor acrítico dos produtos postos no mercado e na mídia.

Diante desse cenário característico da sociedade atual, Cerletti e Kohan (1999, p. 46) abordam a questão de como inserir a filosofia nesse contexto de globalização. Os autores acentuam que, no contexto da sociedade pós-moderna, acabaram sendo formados indivíduos paradoxais: são apresentados como autônomos e capazes de escolher, mas são, de fato, "fragmentados, vacilantes cada vez menos capacitados para escolher, desejar ou criticar aquilo que constantemente consomem." Em suma, tem-se indivíduos acríticos, os quais serão os alunos das aulas de filosofia. Esta, contrariamente, exige uma aguçada capacidade crítica, em virtude da própria natureza das reflexões que propõe. Há, portanto, uma discrepância

(C) Filosofia e Educação - ISSN 1984-9605 - Volume 4, Número 2 Outubro de 2012 - Março de 2013 
entre as exigências impostas pela atividade filosófica e a capacidade dos alunos da escola atual.

Outro problema para a disciplina de filosofia atualmente reside em sua carência de atrativos para os alunos. O homem, na pós-modernidade, está acostumado à recepção passiva e fácil, sem esforço, de informações. Esse é o modelo imposto pela dinâmica atual dos meios de comunicação. A filosofia, ao contrário do que é transmitido pela televisão e pelo computador, exige concentração do indivíduo, que terá que esforçar-se no raciocínio para compreender o que há para ser transmitido por meio de um texto filosófico. Diante disso, a filosofia acaba sendo algo pouco ou nada atrativo para as pessoas, o que acaba prejudicando sua inserção e consolidação na escola.

Dada a pouca atratividade e a falta de postura crítica por parte dos alunos, torna-se um desafio encontrar um lugar para a filosofia na escola atual. Cerletti e Kohan, contudo, pensam que a filosofia não deve se resignar a essa aparente falta de espaço. Eles apontam que a filosofia poderia ser capaz de tornar os indivíduos mais críticos e ajudar na reflexão acerca do mundo em que se vive atualmente. Para tanto, faz-se necessário, contudo, traçar estratégias a serem postas em prática em sala de aula que visem à eliminação dos dois entraves que, na sociedade atual, são postos à filosofia: a falta de postura crítica por parte dos alunos e a pouca atratividade que para eles a filosofia possui. Diante disso, passar-se-á, na sequência, à reflexão acerca de qual metodologia adotar a fim de neutralizar os dois entraves mencionados. Tal metodologia, com efeito, deve considerar a existência deles para que dita neutralização seja possível.

\subsection{Qual estratégia pode ser adotada na aula de filosofia?}

No âmbito da filosofia, existem diferentes métodos e diferentes objetos de estudo. A filosofia, portanto, distingue-se nesse ponto da ciência,

(C) Filosofia e Educação - ISSN 1984-9605 - Volume 4, Número 2 Outubro de 2012 - Março de 2013 
que, em cada uma de suas modalidades, estuda um único objeto e tem um único método, o método científico. Dentre as diferentes metodologias filosóficas que podem ser adotadas nas aulas de filosofia do ensino médio, encontra-se a metodologia oferecida por Gallo (2007), a qual parece se coadunar com a pretensão de neutralizar os dois entraves enfrentados atualmente pela disciplina de filosofia.

Gallo adota a concepção de filosofia endossada por Deleuze e Guattari, segundo a qual ela seria a arte de criar conceitos, entendendo conceito da maneira como anteriormente dito (na seção 1). Tendo essa concepção de filosofia como ponto de partida, Gallo propõe uma metodologia que pode ser adotada nas aulas de filosofia do ensino médio. Tal metodologia baseia-se na idéia de que, durante o processo de ensinoaprendizagem, o aluno deve assumir uma postura ativa. Afinal, se a filosofia é uma arte, ela exige que o aluno, ao aprendê-la, exercite-se na consecução de uma possível "obra final". Vale notar, no entanto, que, em se tratando de filosofia, referida "obra final", entendida como uma resposta definitiva a determinado questionamento filosófico, pode jamais ser obtida; o importante é, por assim dizer, o próprio "processo de produção", ou seja, o próprio filosofar, o qual deve ser experimentado pelo próprio aluno.

Concebendo a filosofia como uma atividade e colocando, assim, o aluno em uma posição ativa, as aulas de filosofia acabarão por ser uma "oficina de conceitos", na expressão de Gallo (2007, p. 25). Sendo uma oficina, Gallo entende que seria adequado que o professor de filosofia estruturasse sua aula de modo a propiciar que o aluno experimente a reflexão filosófica. Para tanto, a oficina de conceitos deveria ser estruturada, para Gallo, em função dos seguintes passos didáticos: (1) sensibilização, (2) problematização, (3) investigação e (4) conceituação. (2007, p. 26)

No primeiro passo, a sensibilização, há que se motivar o aluno ao exercício do pensamento. Para tanto, faz-se necessário "chamar a atenção 
para o tema de trabalho" (Gallo, 2007, p. 27), de forma a propiciar o envolvimento do aluno. Este passo é necessário porque, como dito anteriormente, o pensamento conceitual característico do filosofar inicia-se a partir de um problema concreto, vivido pelo filósofo. O conceito surge, então, como tentativa de equacionar esse problema, de tornar inteligível uma situação caótica vivida pelo filósofo. Mas, se o problema que enseja o filosofar deve ser vivido pelo filósofo, então os alunos da aula de filosofia como oficina de conceitos devem estar suficientemente envolvidos com a temática proposta, para que, num momento posterior, qualquer problema que surja seja um problema de fato vivido por eles. Caso isso não ocorra, eles não experimentarão o filosofar, não porão o pensamento em movimento a fim de obter soluções ao problema.

Após isso, deve-se iniciar um processo de problematização. Eis o momento de "transformar o tema em problema" (Gallo, 2007, p. 28). Nesse momento, o tema que foi inicialmente exposto é problematizado, o que é realizado através de um estímulo à produção, por parte do aluno, de perguntas concernentes ao tema proposto. Ao transformar o tema em problema, surgirá a necessidade de o aluno buscar soluções, o que fará com que o mesmo se dedique à tarefa para, ao final, vir a criar um conceito. (Gallo, 2007, p. 28-29)

Propostas determinadas questões pelos alunos, surge o momento da investigação, que consiste no terceiro passo didático do modelo proposto por Gallo. Durante a investigação é que se recorre à história da filosofia e às soluções que diferentes filósofos forneceram aos problemas, às questões formuladas pelos alunos. Essas soluções ajudarão o aluno a entender melhor os problemas que está investigando e não mais serão vistas como "o centro do currículo, mas como um recurso necessário para pensar o nosso próprio tempo, nossos próprios problemas." (Gallo, 2007, p. 29) A história da 
filosofia, então, será vista como algo que pode ajudar o aluno em sua atividade.

Por fim, a última etapa desse processo seria a conceituação. Para Gallo (2007, pp. 30-31), "nessa etapa final, trata-se de fazer o movimento filosófico propriamente dito, isto é, a criação do conceito.” Nesse momento, o aluno toma aquilo que foi por ele aprendido a respeito do que foi proposto pelos filósofos ao longo da história, seus conceitos, e recria-os a partir de uma tentativa de aplicação ao problema inicial. Caso considere ser possível dita aplicação, o aluno estará recriando um conceito, já que o deslocando do seu contexto original acaba o modificando. Caso o aluno considere insuficientes os conceitos elaborados ao longo da história da filosofia para equacionar o problema sobre o qual está se debruçando, então o aluno poderá criar um conceito filosófico novo, a partir dos elementos fornecidos pela história da filosofia. (Gallo, 2007, pp. 30-31)

Diante da sucinta exposição da metodologia proposta por Gallo, pode ser percebido que a mesma está em harmonia com o que anteriormente foi dito a respeito do que deve ser ensinado nas aulas de filosofia, a saber, o próprio filosofar, embora embasado na história da filosofia. Ademais, a existência do primeiro passo didático, a sensibilização, é uma maneira de tornar a filosofia mais atrativa para os alunos, que visualizam uma vinculação dela com seu quotidiano. Com relação à falta de postura crítica por parte do aluno, pode-se dizer que a mesma será minimizada através da estimulação de reflexões filosóficas em sala de aula. Com o passar do tempo, será formado no aluno até mesmo o hábito de posicionar-se criticamente frente a temas diversos pela iniciativa da criação conceitual em filosofia. Sendo assim, considera-se a metodologia de Silvio Gallo uma excelente estratégia para neutralizar os entraves que a filosofia enfrenta no ensino médio e, desse modo, possibilitar que a disciplina cumpra sua função nessa fase da educação básica.

(C) Filosofia e Educação - ISSN 1984-9605 - Volume 4, Número 2 Outubro de 2012 - Março de 2013 


\section{Considerações finais}

Diante de todo o exposto ao longo deste trabalho, chega-se à conclusão de que uma aula de filosofia, dada a própria natureza que a filosofia possui, deve ensinar os alunos a filosofar, tendo-se em conta os procedimentos desenvolvidos por diferentes filósofos ao longo da história. Com isso, estarse-ia efetuando uma contribuição substancial para que os alunos passem a pensar de modo autônomo, isto é, buscando razões, e não o critério da autoridade para sustentar seus posicionamentos. Ademais, a filosofia poderia contribuir para que o aluno tenha uma visão mais ampla e articulada dos conhecimentos que adquire na escola, ou mesmo fora dela. E, por fim, a disciplina de filosofia poderia proporcionar ao aluno a oportunidade de exercitar-se na atividade de criação de conceitos, oportunidade esta que poderá, quem sabe, jamais ter novamente. Tais seriam as contribuições que a disciplina de filosofia pode fornecer aos alunos do ensino médio, as quais devem pautar a organização das aulas por parte do professor de filosofia. Dentre essas contribuições, contudo, vale notar que apenas a última citada seria exclusiva da disciplina de filosofia e, portanto, capaz de justificar sua presença no ensino médio.

Entretanto, foi detectada a existência de dois entraves principais para a disciplina de filosofia no ensino médio, os quais são decorrentes das características da sociedade pós-moderna em que se vive, quais sejam, a falta de postura crítica por parte dos alunos e a pouca atratividade que para eles a filosofia possui. A fim de neutralizar ditos entraves, então, propõe-se, no presente trabalho, o recurso à metodologia desenvolvida por Silvio Gallo. Considera-se que o emprego de tal metodologia seria capaz de neutralizar os entraves mencionados e, assim, permitir que a disciplina de filosofia cumpra seu papel no ensino médio.

(C) Filosofia e Educação - ISSN 1984-9605 - Volume 4, Número 2 Outubro de 2012 - Março de 2013 
Esses foram, em suma, os pontos tocados no decorrer deste artigo. Não obstante, há vários aspectos que foram aqui negligenciados e que são merecedores de maiores comentários. Um deles consiste na aceitação da justificativa da presença da filosofia nos currículos de ensino médio por parte de pessoas que não conhecem filosofia. Quando se adentra nessa espécie de discussão, sobre a justificativa da presença da filosofia no ensino médio, há que se ter presente que a mesma envolve pessoas que não estudam filosofia e que, talvez, jamais com ela tenham tido contato. Além disso, não se pode esquecer que tais pessoas precisam ser convencidas de que a filosofia deve estar no currículo, visto que a inclusão e manutenção dessa disciplina no currículo depende de questões legais, decididas não apenas por pessoas que conhecem filosofia. Diante disso, cabe indagar: será que a argumentação desenvolvida por Gallo, baseada num argumento filosófico ancorado na filosofia de Deleuze e Guatarri, convenceria aquelas pessoas envolvidas na discussão mas que não possuem conhecimentos filosóficos? Por mais que se possa dizer, como aqui se faz, que o argumento de Gallo é bom, sólido e capaz de justificar a presença da disciplina de filosofia no ensino médio, resta ainda aberta a possibilidade de que o mesmo não convença pessoas que são de outras áreas. Isso porque o convencimento de uma pessoa depende de fatores psicológicos, de suas crenças, etc., de modo que nem sempre um bom argumento obtém êxito em convencer as pessoas. Uma pessoa pode, por exemplo, ter uma crença falsa, na qual crê com uma firmeza quase inabalável, e esta crença impedir que essa pessoa aceite, seja convencida por determinado argumento, mesmo que ele seja sólido.

Sendo assim, o debate acerca da justificativa da presença da filosofia no ensino médio acaba trazendo dificuldades aos filósofos nele envolvidos: por um lado, tenta-se, como requerido na filosofia, apresentar bons argumentos, baseados em concepções filosóficas sobre a natureza da 
filosofia, que mostrem que a filosofia merece estar no currículo de ensino médio; por outro lado, há a dificuldade de convencer os não filósofos, pelo fato de estes não compreenderem a concepção filosófica que baseia o argumento, por não a aceitarem (em virtude, por exemplo, de uma crença que tenham previamente e que pareça colidir com a concepção filosófica em questão) ou por sequer a tomarem em consideração para aferir se ela é aceitável. Esta questão é de suma importância para a comunidade brasileira de professores de filosofia, já que o debate em questão envolve não filósofos, e merece uma abordagem mais detida que não cabe a este artigo.

Outro ponto importante não mencionado neste trabalho é que a reduzida carga horária reservada para a disciplina de filosofia na maioria das escolas, que, em geral, deixam para a disciplina apenas um período semanal (ou dois períodos, conforme a escola), traz empecilhos práticos para que a filosofia cumpra seu papel no ensino médio. A questão que se impõe é a seguinte: tendo geralmente menos de uma hora semanal para ministrar aulas de filosofia em cada turma, como pode o professor conseguir aplicar a estratégia dos quatro momentos de Gallo a fim de estimular seus alunos a filosofar? Em uma aula apenas, isso não parece ser possível. Ademais, mesmo que os quatro momentos não sejam aplicados a cada aula, mas a blocos de aulas (que compõem uma unidade didática, por exemplo), é difícil saber como pode haver uma continuidade entre cada uma das aulas, de forma que o trabalho desenvolvido em uma aula tenha a adequada continuidade na aula seguinte sem a perda do interesse por parte dos alunos.

Imagine-se, por exemplo, que o professor distribua os momentos em quatro aulas, sendo cada uma destinada para um dos momentos ${ }^{1}$. Na primeira aula, então, ele realiza a sensibilização. Na segunda aula, após uma semana na qual o aluno se envolve com atividades diversas, escolares e não

${ }^{1}$ Poder-se-ia pensar em outras formas de dividir os momentos didáticos, como, por exemplo, dividi-los em duas ou três aulas. Porém, mesmo que a distribuição fosse modificada, o problema da descontinuidade persistiria.

(C) Filosofia e Educação - ISSN 1984-9605 - Volume 4, Número 2

Outubro de 2012 - Março de 2013 
escolares, é a ocasião em que deverá ser feita a problematização. Mas será que o aluno ainda estará interessado como talvez estivesse no final da primeira aula, quando foi feita a sensibilização? Salvo se o aluno tiver um interesse muito grande em filosofia, sobrepondo-a a outras atividades que realiza, é provável que o interesse pelo tema proposto tenha se perdido consideravelmente, perdendo-se, pelo menos parcialmente, o efeito da sensibilização.

A limitada carga horária da disciplina de filosofia no ensino médio, então, parece ser uma barreira prática relevante para a implementação da metodologia de Gallo, a qual foi aqui considerada como uma excelente estratégia para possibilitar que a filosofia cumpra seu papel no ensino médio. Esta questão, bem como sobre como argumentar e convencer não filósofos da necessidade da presença da filosofia no ensino médio, são questões deixadas em aberto neste momento, mas que são dignas de consideração mais detida, a ser realizada em trabalhos futuros.

\section{Bibliografia}

ASPIS, R. P. L. O professor de filosofia: o ensino de filosofia no ensino médio como experiência filosófica. Cad. Cedes, Campinas, vol. 24, n. 64, p. 305-320, set./dez. 2004. Disponível em <http://www.cedes.unicamp.br>. Acesso em: 22 Nov. 2010.

CERLETTI, Alejandro A.; KOHAN, Walter O. As condições atuais da filosofia da escola. In: A filosofia no ensino médio. Tradução de Norma Guimarães Azeredo. Brasília: Editora Universidade de Brasília,1999.

GALLO, Sílvio. A filosofia e seu ensino: conceito e transversalidade. In: SILVEIRA, Renê J. T. Silveira; GOTO, Roberto (Orgs). Filosofia no ensino médio: temas, problemas e propostas. São Paulo: edições Loyola, 2007. GALLO, S.; KOHAN, W. Filosofia no ensino médio. Petrópolis: Vozes, 2000.

(C) Filosofia e Educação - ISSN 1984-9605 - Volume 4, Número 2 Outubro de 2012 - Março de 2013 
OBIOLS G. Uma introdução ao ensino da filosofia. Ijuí: Editora da UNIJUÍ, 2002. 